\title{
Uma tentativa de integração entre Keynes e Kalecki: investimento e dinâmica
}

\author{
An attempt to integrate Keynes and Kalecki: \\ investment and dynamics
}

\author{
MARIA ISABEL BUSATO* \\ ANA CRISTINA REIF** \\ MARIO LUIZ POSSAS $* * *+$
}

\begin{abstract}
RESUMO: Keynes e Kalecki foram os precursores dos modelos de dinâmica baseados no Princípio da Demanda Efetiva e atribuíram ao investimento papel central para aquela. Kalecki retrata uma dinâmica cíclica regular associada ao efeito dual e defasado do investimento. Já o modelo de Keynes descreve uma dinâmica potencialmente instável, resultado das decisões baseadas em expectativas formuladas sob incerteza. Este artigo tem como objetivo construir uma interpretação integradora das visões dos autores, possibilitando uma melhor compreensão dos fatos estilizados que mostram que a dinâmica capitalista é marcada por fases de regularidade cíclica que são eventualmente quebradas, dando lugar à instabilidade. PALAVRAS-CHAVE: Dinâmica; investimento; ciclo; instabilidade; princípio da demanda efetiva.
\end{abstract}

ABSTRACT: Keynes and Kalecki were the forerunners of the models of economic dynamics based on the Principle of Effective Demand (PDE) and assigned central role to investment for understanding dynamics. Kalecki's model describes a regular cyclical dynamics - with well-marked standard - associated with dual and lagged investment effect. Keynes's model in turn describes a potentially unstable dynamics, a result of the decisions of agents whose expectations are formed under conditions of uncertainty. This article aims to build an integrated interpretation of Keynes and Kalecki's views, enabling a better understanding of the stylized facts that show that the capitalist dynamic is marked by phases of cyclical regularity that are eventually and suddenly broken, leading to instability.

KEYWORDS: Dynamics; investment; cycle; instability; principle of effective demand. JEL Classification: E12; E11; E22.

\footnotetext{
* Professora do Instituto de Economia da Universidade Federal do Rio de Janeiro - IE/UFRJ, Rio de Janeiro/RJ, Brasil. E-mail: maria.busato@ie.ufrj.br; https://orcid.org/0000-0002-6684-1318.

** Professora do Instituto de Economia da Universidade Federal do Rio de Janeiro - IE/UFRJ, Rio de Janeiro/RJ, Brasil. E-mail: ana.reif@ie.ufrj.br; https://orcid.org/0000-0002-9097-0849.

*** Professor Titular do Instituto de Economia da Universidade Federal do Rio de Janeiro - IE/UFRJ, Rio de Janeiro/RJ, Brasil. E-mail: mariopossas@gmail.com. https://orcid.org/0000-0002-7435-3250. Submetido: 2/janeiro/2018; Aprovado 22/dezembro/2018.

+ Os autores são membros do Grupo de Dinâmica Econômica do Instituto de Economia da Universidade Federal do Rio de Janeiro.
} 


\section{INTRODUÇÃO: LINHAS GERAIS DE UMA INTEGRAÇÃO POSSÍVEL}

A dinâmica capitalista compreende dois movimentos básicos, ciclo e tendência. Os ciclos - objeto de discussão deste artigo - podem ter sua periodicidade regular, ou podem tomar a forma de flutuações não regulares, sujeitas a instabilidade e a crises ${ }^{1}$. Modelos que adotam o Princípio da Demanda Efetiva (PDE) normalmente atribuem ao investimento papel central para explicar as flutuações cíclicas do produto e do emprego. Keynes e Kalecki foram os precursores dos modelos que adotam o PDE como referência e, tanto para o primeiro como para o segundo, o investimento é a variável-chave para a compreensão da dinâmica capitalista.

No modelo teórico construído por M. Kalecki (1977, [1954]), a interação entre os efeitos multiplicador e acelerador do investimento dá lugar a uma dinâmica, que em última análise está associada às decisões de investir. Estas são guiadas pelo princípio do ajustamento do estoque de capital, de tal forma que os efeitos 'demanda' e 'capacidade', defasados entre si, criam conjuntamente uma dinâmica cíclica do investimento e, como consequência, do produto e do emprego.

No modelo de Keynes, conceitos como os de eficiência marginal do capital $(\mathrm{EMgK})$ e de taxa de juros são fundamentais para a tomada de decisões de investir. Nos dois conceitos estão presentes as expectativas que os agentes formulam sobre o curso dos eventos futuros. A tomada de decisões de investir, via cálculo probabilístico, escapa aos agentes, que são "obrigados" a tomar suas decisões num ambiente de incerteza ${ }^{2}$. Nessa visão, a impossibilidade de se atribuir probabilidade objetiva à ocorrência dos eventos futuros, associada à impossibilidade de uma decisão errônea ser facilmente revertida, tornaria o investimento volátil e, com ele, o produto e o emprego.

Tendo em vista essas considerações teóricas, Kalecki, por um lado, foi muitas vezes legitimamente acusado por autores pós-keynesianos de ter construído um modelo mecanicista, por explicar flutuações 'bem-comportadas', mas sem fornecer uma análise adequada das flutuações não regulares ou da instabilidade. Por outro lado, Keynes, devido à incerteza associada às decisões de investir, teria construído um modelo com baixa capacidade preditiva. Na visão mais difundida entre aqueles que buscam compreender a contribuição de Keynes, as contínuas revisões de expectativas não permitem que se façam projeções minimamente confiáveis, o que resultaria em trajetórias indeterminadas.

Fatos estilizados mostram, no entanto, que as principais variáveis macro agre-

\footnotetext{
${ }^{1} \mathrm{O}$ conceito de ciclo é herdado da física e normalmente envolve a alternância regular de períodos de crescimento e de declínio da atividade econômica. Neste artigo, a regularidade cíclica é compreendida como uma possibilidade sem, contudo, esgotar o conceito.

${ }^{2}$ Davidson (1972, p.18) afirma que "production and investment decisions because they involve the passage of time involve uncertainty as to costs, the market value of the final end-product, and the actual future dates, when the end product will be marketed".
} 
gadas - produto, emprego e massa de lucro - flutuam com certa regularidade, a qual é eventualmente e repentinamente quebrada, dando lugar à instabilidade.

Este artigo busca integrar as visões de Keynes e de Kalecki para, conjuntamente, procurar dar conta deste importante fato estilizado ${ }^{3}$. Para tanto, tiraremos o foco central da contribuição de Keynes das contínuas revisões nas expectativas como geradora das mudanças súbitas, e daremos maior ênfase aos conceitos de convenção e de grau de confiança que este autor atribuiu a elas.

Não são simplesmente as expectativas, pensadas por Keynes e ausentes explicitamente em Kalecki, que fornecem a base para explicar as flutuações inesperadas e repentinas em seu modelo. O grau de confiança que os agentes associam a tais expectativas e suas mudanças repentinas são o principal fator para explicar as súbitas e amplas flutuações.

Conforme esclarece Keynes no capítulo 12 da T.G. (Teoria Geral), as expectativas de longo prazo sobre as decisões de investir formuladas em seu esquema teórico estão fundadas, na medida do possível, em bases 'objetivas'. Ao formar expectativas sobre o futuro incerto, os agentes darão maior peso aos fatos que são conhecidos, pois não seria sensato dar um peso muito grande àqueles fatores que não o são ${ }^{4}$. Em momentos de 'normalidade', os agentes levarão em conta aqueles fatores que são 'mais ou menos' conhecidos - o estado atual das coisas -, os quais 'merecem nossa confiança'. Ou seja, agentes adotam um comportamento convencional, cuja principal forma consiste em projetar o presente para o futuro.

Nesses momentos de 'normalidade', quando os agentes adotam comportamento convencional, o modelo de Kalecki - e sua formulação das decisões de investir, com o investimento sendo induzido pelo nível e taxa de mudança no nível de atividade - é uma boa aproximação do modo como os agentes decidem, gerando uma dinâmica com padrão definido. No entanto, seu modelo tomado isoladamente é incompleto, porque não é capaz de explicar as mudanças repentinas, não esperadas, em decorrência de o modelo assumir que o investimento é fundamentalmente induzido pelo grau de utilização da capacidade.

Para resolver esse problema é preciso atribuir confiança às expectativas formuladas com base na "teoria prática do futuro". Não é de surpreender que a confiança depositada nestas expectativas seja tão frágil e sujeita a mudanças repentinas - o que, via flutuação do investimento, causa instabilidade no sistema econômico.

Desse modo, consideramos que as análises em conjunto desses dois autores permitem uma melhor compreensão da dinâmica econômica capitalista, marcada por fases de (i) estabilidade ou de "normalidade", que ocorrem quando as convenções estão vigentes e há razões para se acreditar que o estado atual das coisas permanecerá aproximadamente como está - o que se traduz essencialmente numa di-

\footnotetext{
${ }^{3}$ Estamos discutindo, como em Kalecki (1954), uma economia sem inovação, mudanças nas preferências, na política econômica e outras mudanças estruturais.

${ }^{4}$ Keynes (1982 [1936], p.124).
} 
nâmica econômica cíclica 'bem-comportada', conforme previsto por Kalecki; e de (ii) instabilidade do sistema, que ocorrem quando a confiança atribuída às expectativas de longo prazo é fraca ou se rompe, quebrando as convenções que ancoravam a tomada de decisões e dando lugar a uma dinâmica instável.

O artigo se organiza da seguinte forma: a segunda e terceira seções analisam respectivamente os fundamentos teóricos dos determinantes do investimento em Kalecki e em Keynes, ressaltando a dinâmica associada a cada um deles em suas interpretações mais reconhecidas; a quarta seção busca fazer uma integração entre as duas contribuições; na última seção são apresentadas as conclusões.

\section{KALECKI: INVESTIMENTO E CICLO}

Esta seção está baseada na obra principal de Kalecki, Teoria da Dinâmica Econômica (1977 [1954]) e apresentará uma síntese das decisões de investir na visão do autor, ressaltando seus desdobramentos para a dinâmica cíclica e abstraindo os fatores de tendência. É desnecessário fazer uma incursão muito detalhada em seu modelo $^{5}$; faremos a seguir apenas uma apresentação daqueles elementos que serão necessários para a construção do argumento de integração proposto.

Em um modelo simplificado - fechado e sem governo -, a demanda agregada é definida pela soma das decisões de consumo e de investimento. Num período curto, as decisões de consumo são essencialmente induzidas pelos lucros e salários, determinados por decisões passadas de investimento em conjunto com a propensão a consumir dos capitalistas e pela distribuição de renda ${ }^{6}$. Logo, as variações no produto dependem de variações no investimento, que, por sua vez, dependem essencialmente de mudanças no grau de utilização da capacidade produtiva.

Kalecki descreve um sistema estruturalmente estável, abstraindo mudanças tecnológicas, de padrões de consumo, de estruturas de mercado e concorrência, de política econômica e das condições externas. Seu objetivo é captar os aspetos centrais da dinâmica econômica e mostrar que, sob uma estrutura dada, as economias capitalistas não tendem para um 'equilíbrio geral', mas apresentam uma dinâmica cíclica, que reflete a dinâmica da demanda efetiva, de indução do nível de atividade ${ }^{7}$.

Ele resume como principais determinantes das decisões de investimento em capital fixo: (i) o nível e a taxa de modificação do nível de atividade; e (ii) aquilo que chamou de 'fatores de desenvolvimento' (com destaque para as inovações). Em sín-

\footnotetext{
${ }^{5}$ Para uma análise mais detalhada ver Kalecki (1977 [1954], caps. 8, 9, 11 e 13); Kalecki (1977 [1968]); Possas (1987).

${ }^{6}$ Kalecki diferencia as decisões de consumo entre capitalistas e trabalhadores. Os primeiros possuem maior grau de autonomia em comparação aos segundos, que consomem suas rendas salariais correntes (no modelo simplificado, o autor supõe que a propensão a consumir dos trabalhadores é igual a um e sem defasagem).

${ }^{7}$ Possas (1987).
} 
tese, as decisões de investir seguem o 'princípio do ajustamento do estoque de capital' e podem ser assim expressas:

$$
F_{t+\tau}=a S_{t}+b \frac{\Delta P_{t}}{\Delta t}-c \frac{\Delta K_{t}}{\Delta t}+d
$$

A equação (1) resume o investimento em capital fixo no período $\left(F_{t+\tau}\right)$ cujas decisões foram tomadas no período $t$, em função crescente da poupança (aSt) e da variação na massa de lucro $\left(b \Delta P_{t} / \Delta t\right)$ e decrescente da ampliação do estoque de capital $\left(c \Delta K_{t} / \Delta t\right)$ Os coeficientes $a, b$ e $c$ são positivos e " $d$ " representa os fatores de desenvolvimento (sujeitos a mudanças no longo prazo).

A poupança como aparente determinante do investimento seria, segundo Possas (1987), um absurdo lógico. Na verdade, St é proxy do lucro retido após distribuição (poupança das empresas), ou seja, é proxy de acumulação interna de lucros, que aumenta a relação capital próprio/dívida, um indicador de risco útil para determinar as condições de acesso ao crédito e/ou ao mercado de capitais de acordo com o "Princípio do Risco Crescente" deste autor, ampliando assim a disponibilidade de recursos para o investimento. No entanto, a forma linear proposta por Kalecki para essa expressão não é a mais adequada. Na verdade, o acesso ao crédito deveria funcionar como uma restrição. O próprio autor afirma em diversas passagens do capítulo 9 de (1977, [1954]) que, "se o investimento for desejado", o acesso ao crédito é relevante para que ele se realize. Com isso, o acesso ao crédito deveria ser incluído na forma de restrição - de teto - que pode limitar ou sancionar o investimento se ele for desejado, mas não determiná-lo. O crédito passaria a ser um condicionante e não determinante das decisões de investir8.

Em conjunto, $\left(\Delta P_{t} / \Delta t\right)$ e $\left(\Delta K_{t} / \Delta t\right)$ mostram o que chamamos de "princípio do ajustamento do estoque de capital" e representam uma proxy para o grau de utilização da capacidade. Se a demanda efetiva se expande, refletida em $\left(\Delta P_{t} / \Delta t\right)$, para dadas condições estruturais, as decisões de investimento respondem positivamente, mas quando o capital novo entra em operação, expresso em $\Delta K t$, provoca queda na taxa de lucro ou redução do grau de utilização, desestimulando novas decisões. Nas palavras de Kalecki (1977, [1954] p.119) "da mesma forma que uma elevação dos lucros dentro do período considerado torna convidativos projetos de investimento adicional, a acumulação de capital tende a restringir os limites dos planos de investimento".

A interação entre os efeitos multiplicador e acelerador "pode produzir trajetórias muito diferentes em função dos parâmetros estruturais e de comportamento introduzidos no modelo, incluindo-se aí as defasagens" (Possas e Baltar, 1983). Mudanças concorrenciais podem levar a mudanças no grau de concentração do mercado, afetando a distribuição entre salários e lucros e o multiplicador; resultado equivalente seria obtido se houvesse alterações nas propensões a consumir das classes. Aumentos no investimento autônomo (p. ex., em inovação) levam também

\footnotetext{
${ }^{8}$ Idem.
} 
a um aumento do investimento induzido em etapas subsequentes, podendo gerar uma trajetória de crescimento com ciclo ${ }^{9}$. Contudo, abstrairemos de tais mudanças, dando ênfase, conforme fez o autor, à análise dos determinantes do investimento sob uma dada estrutura.

A flexibilização das condições estruturais acima mencionadas tira o modelo de Kalecki do ciclo 'puro' e pode levar a uma trajetória de ciclo em torno de uma tendência. Segundo Lopez e Mott (1999, p.293), Kalecki deseja explicar por que nas economias capitalistas o "long-run growth goes hand in hand with cyclical movements around the trend". Neste artigo estamos especialmente interessados em sua teoria do ciclo puro, que dará suporte para a construção da integração pretendida.

\section{Dinâmica cíclica associada às decisões de investir em Kalecki}

Conforme exposto acima, as decisões de investir e o investimento efetivamente realizado dependem do nível e da taxa de modificação do nível de atividade econômica, considerando certo hiato temporal, o que, segundo Kalecki (1977 [1954], p.143), "fornece a base para uma análise do processo econômico dinâmico e em particular nos permite demonstrar que esse processo envolve flutuações cíclicas”. Kalecki distingue claramente três etapas relativas ao papel do investimento: a tomada de decisões, os gastos em investimento e o início da operação do novo capital. A dinâmica associada ao investimento, considerada tal temporalidade, gerará o ciclo puro proposto por Kalecki - com reversão automática -, podendo ser regular, explosivo ou amortecido. Ele envolve um mecanismo de recuperação 'natural', na terminologia de Kalecki (1977, [1935]).

Resumidamente, a natureza dessa dinâmica cíclica pode ser compreendida: Um aumento nos gastos em investimento aumenta a demanda e a massa de lucro, o que impulsiona nova rodada de aumento no investimento, dados os valores dos parâmetros. Enquanto a taxa de decisões de investir superar a taxa de incorporação de capital novo, o grau de utilização estará aumentando e nos encontraremos em fase expansiva do ciclo econômico. Decorrido algum tempo, de acordo com as defasagens específicas, a nova capacidade produtiva começa a entrar em operação, o estímulo do crescimento e dos lucros passa a ser compensado pelo desestímulo gerado pela ampliação da capacidade produtiva, podendo fazer com que - dependendo dos valores dos parâmetros - a economia entre em fase de declínio, que será revertida quando o elevado nível de desinvestimento provocado pela depreciação compense a trajetória descendente do nível de atividade e dos lucros, aumentando o grau de utilização e provocando o início da recuperação.

A dinâmica assim produzida e associada ao investimento, na contribuição de

\footnotetext{
${ }^{9}$ Se incluirmos o governo e o setor externo, teremos como resultado que aumentos no déficit público ou nas exportações líquidas elevarão a demanda e a renda, conforme o efeito multiplicador, aumentando o grau de utilização, afetando positivamente a massa de lucro, induzindo o investimento por meio do acelerador.
} 
Kalecki, é uma dinâmica essencialmente cíclica (para valores razoáveis dos parâmetros), podendo ser estável, amortecida ${ }^{10}$ ou explosiva. O conceito de ciclo em Kalecki é mais próximo daquele herdado da física, que normalmente envolve a alternância regular de períodos de crescimento e de declínio da atividade econômica, com alternância entre fases de recuperação e expansão por períodos de recessão e depressão. E, embora Kalecki tenha mencionado expectativas em diversas passagens ${ }^{11}$, muitos de seus intérpretes afirmam que em:

his theory the weight is given entirely to 'objetive' fators. He insisted that capitalists did not react solely, or mainly to their expectations, but rather to the 'hard fact' (López e Mott, 1999, p.294)

O modelo Kaleckiano explica as decisões de investir e a dinâmica associada a tais decisões a partir de influências autônomas e induzidas. A principal influência indutora seria o efeito dual e defasado do investimento acima descrito. As influências autônomas dizem respeito às constantes sujeitas a modificações de longo prazo, com destaque para os fatores de desenvolvimento, como inovações, que conferem a tendência de crescimento à economia. Este modelo não contempla elementos capazes de explicar as instabilidades e crises, a menos que se inclua algum fator exógeno ausente originalmente em seu modelo ${ }^{12}$.

\section{DECISÕES DE INVESTIR E DINÂMICA EM KEYNES: UMA LEITURA}

Keynes tinha como objetivo construir uma teoria que fosse capaz de explicar por que o produto e o emprego são o que são em cada momento do tempo. Seu método para tanto fica claro na T.G. Nos capítulos 2 a 5 ele consolida as bases de seu argumento, ao afirmar que o produto e o emprego são determinados pelo PDE; e nos seguintes, até o capítulo 18 , discute os determinantes do consumo e do investimento, os dois principais componentes da demanda agregada, em um modelo simplificado, sem governo e sem transações com o exterior. O consumo é em grande medida induzido pela renda, recaindo sobre o investimento o papel central para explicar as flutuações da demanda, do produto e do emprego. Keynes (1984 [1937], p.178) sumariza o argumento afirmando que sua teoria

\footnotetext{
${ }^{10}$ Lembrando que, segundo Kalecki (1977 [1954], p.152), podemos ser tentados a pensar que "no caso das flutuações amortecidas, a amplitude irá declinar continuamente, de forma que nesse caso poderia parecer que o ciclo vai diminuindo até tornar-se insignificante. Contudo, isso não está correto", pois seria preciso incluir um componente estocástico na equação que representa o investimento líquido de Kalecki e cuja inclusão fará com que o ciclo amortecido tome a forma de um ciclo semirregular.

${ }^{11}$ Kalecki (1977 [1954], p. 177); Kalecki (1977[1943], p.55 e p.59).

12 Observando que o componente estocástico sugerido no capítulo 13 da Teoria da Dinâmica Econômica (Kalecki, 1977 [1954]) não explica instabilidades, gerando apenas uma dinâmica cíclica semirregular.
} 
[...] pode ser resumida pela afirmação de que, dada a psicologia do público, o nível da produção e do emprego como um todo depende do montante do investimento. Eu a proponho desta maneira, não porque este seja o único fator de que depende a produção agregada, mas porque, num sistema complexo, é habitual considerar como causa causans o fator mais sujeito a repentinas e amplas flutuações.

Os elementos centrais de sua teoria das decisões de investir estão presentes no Livro IV da T.G. e no artigo de 1937, intitulado "A Teoria Geral do Emprego" (Keynes, 1984 [1937]). As decisões de investir dependem fundamentalmente da relação entre EMgK e taxa de juros. Nos dois conceitos estão implícitas as expectativas dos agentes.

A eficiência marginal depende das avaliações dos capitalistas a respeito do fluxo esperado de rendimento de um ativo de capital, comparado com o preço de oferta de tal ativo (ou custo de reposição). Keynes (1982 [1936], p.115) nos dá a seguinte definição para $\mathrm{EMgK}$ :

[...] defino a eficiência marginal do capital como sendo a taxa de desconto que tornaria o valor presente do fluxo de anuidades das rendas esperadas desse capital, durante toda a sua existência, exatamente igual ao seu preço de oferta.

A avaliação do rendimento esperado do bem de capital ao longo de sua vida útil, por sua vez, depende, fundamentalmente, das expectativas de longo prazo. Contudo, Keynes (1982 [1936], p.124) salienta que "o estado da expectativa a longo prazo, que serve de base para as nossas decisões de investir, não depende, exclusivamente, do prognóstico mais provável que possamos formular. Depende, também, da confiança com a qual fazemos este prognóstico". Afirmando:

O fato de maior importância é a extrema precariedade da base do conhecimento sobre o qual temos que fazer os nossos cálculos das rendas esperadas. O nosso conhecimento dos fatores que regularão a renda de um investimento alguns anos mais tarde é, em geral, muito limitado e, com frequência, desprezível. (Keynes, 1982]1936], p.125).

Não existe, portanto, base científica para o cálculo probabilístico; “apesar disso, a necessidade de [...] tomada de decisões obriga-nos, como homens práticos, a fazer o máximo para esquecer esse fato incômodo e a nos comportar exatamente como deveríamos se tivéssemos atrás de nós um bom cálculo [...] sobre a série de vantagens e desvantagens futuras" ${ }^{\prime 3}$. Por este motivo os agentes recorrem à convenção para dar suporte às suas expectativas de longo prazo. $\mathrm{O}$ comportamento convencional utilizado pelos agentes consiste em "supor que o presente é um bom guia para o futuro, ou o que é

${ }^{13}$ Keynes (1984 [1937]). 
quase equivalente, acreditar que o estado atual das coisas se reproduzirá por algum tempo" ${ }^{14}$. Enfim, ele ressalta que o fluxo de receita esperada dos ativos pode ser calculado dando maior ênfase aos fatores sobre os quais nosso conhecimento é mais certo (1984 [1937], p.172), dentre os quais podemos citar o grau de utilização, que expressa a demanda corrente, os preços atuais e a concorrência.

No artigo de 1937 essa noção fica mais clara, e Keynes visivelmente está ressaltando a importância das convenções através do que denominou a "teoria prática do futuro", que suporta as decisões de investimento produtivo no sentido de considerar o comportamento da maioria ou da média e/ou de projetar a situação atual para o futuro. A principal racionalidade por trás desse tipo de comportamento é a autorrealização ${ }^{15}$. Às expectativas de receita esperada assim calculadas, estão associados os níveis de confiança que os agentes depositam nelas.

O outro elo da determinação do investimento, a taxa de juros, é, segundo Keynes (1982 [1936], p.137) “o 'preço' mediante o qual o desejo de manter a riqueza em forma líquida se concilia com a quantidade de moeda disponível”, ou, em outras palavras, "é a recompensa por não entesourar" (Keynes, 1982 [1936], p.142).

A moeda é considerada um ativo no esquema teórico de Keynes porque apresenta uma rentabilidade esperada positiva - por ele denominada de "prêmio de liquidez" - o que, por sua vez, decorre de possuir liquidez máxima, imediata e constituir reserva de valor ante a incerteza quanto à variação de valor e rentabilidade dos demais ativos.

Quando se adota uma perspectiva mais pessimista a respeito de futuros rendimentos, não existe razão para que haja uma reduzida propensão a entesourar. $\mathrm{Na}$ verdade, as condições que agravam um dos fatores tendem, via de regra, a agravar o outro. (Keynes, 1984, p.175)

Quando a confiança nas expectativas é fraca, a EMgK normalmente cai, e a retenção de moeda, motivada por tal pessimismo, tende a elevar a taxa de juros. Há uma sequência nesse processo. O que desencadeia a mudança na composição do portfólio é a queda da confiança. Keynes afirma que

a preferência pela liquidez, exceto nas suas manifestações associadas ao aumento da atividade comercial e da especulação, só começa a aumentar após o desmoronamento da eficiência marginal do capital. (Keynes, 1982, p.245)

Essa passagem evidencia que é a queda no grau da confiança, em geral associada a uma quebra da convenção, quem inicia o processo. A elevação da preferência pela liquidez é a materialização da reação.

\footnotetext{
${ }^{14}$ Idem.

${ }^{15}$ Possas (2015).
} 
Em síntese, as condições que reduzem a expectativa de ganhos futuros vêm junto com as que aumentam as taxas de juros, pois a queda do grau de confiança de que o estado atual das coisas permanecerá como vinha ocorrendo leva ao aumento da preferência pela liquidez, aumentando a taxa de juros (Keynes, 1984, p.173-4; Keynes, 1982, p.245). Não é de estranhar que o investimento esteja tão sujeito a mudanças. Essa instabilidade é assim expressa por Keynes (1984, p.175):

Não é surpreendente que o volume de investimento [...] flutue muito através do tempo. Isso porque ele depende de dois conjuntos de opiniões sobre o futuro - nenhum dos quais se apoia num fundamento adequado ou seguro -, sobre a propensão a entesourar e sobre a futura rentabilidade dos ativos de capital.

Boa parte dos autores que utilizam a Teoria Geral ressaltando a incerteza não probabilística sobre o comportamento e as decisões dos agentes ressalta a instabilidade associada ao funcionamento de uma economia monetária de produção. Davidson (1972, p.114) assim expressa essa ideia:

In an uncertain world where growth is the aggregated effect of a great number of individual decisions and since individual decisions are based on trial and error, it is unlikely that an economy will be able to maintain an unchanging $[\ldots]$ rate of growth.

A instabilidade do sistema estaria associada ao fato de que agentes econômicos tomam decisões e formam suas expectavivas baseados num futuro não cognocível, impossibilitando a adoção de expectativas endógenas. A precariedade de bases objetivas sobre as quais se formulam as expectativas tornaria a $\mathrm{EMgK}$ muito volátil e, com ela, o investimento.

No entanto, conforme mencionado anteriormente e mais bem explorado na seção seguinte, pretendemos argumentar que a própria existência de incerteza leva os agentes a adotarem um antídoto contra a mesma através da adoção de posturas que os protegem minimamente dela, na forma de comportamento convencional. Claro está que esse tipo de comportamento não elimina a incerteza, mas ancora por algum tempo as decisões, dando estabilidade ao sistema e o tornando apenas potencialmente instável.

$\mathrm{Na}$ abordagem que se pretende construir em seguida, pode-se extrair das contribuições de Keynes não apenas uma teorização capaz de explicar as alternâncias desprovidas de padrões definidos - flutuações ou crises -, mas também uma fundamentação, com base no conceito de incerteza, para as trajetórias assumidas nos períodos de normalidade e sem mudanças bruscas, quando o sistema tende a se comportar aproximadamente como Kalecki sugere. 
Conforme apresentado nas seções anteriores, a partir da contribuição de Kalecki sobre os determinantes do investimento foi possível explicar flutuações "bem-comportadas”, expressas nos ciclos econômicos regulares. Por outro lado, a TG, em algumas de suas interpretações, implica que a influência da incerteza sobre os processos decisórios conduz a dinâmicas essencialmente instáveis.

Pretende-se mostrar que a integração dos dois autores permite uma melhor compreensão da dinâmica econômica capitalista em seu conjunto, caracterizada por fases cíclicas com certa regularidade, que podem se romper dando lugar à instabilidade e às crises. De Keynes, além das expectativas formadas sob incerteza, tomaremos os conceitos de grau de confiança e de convenção, enquanto de Kalecki tomaremos seu modelo mais completo e analítico sobre as decisões capitalistas de investir.

Em diversas passagens, Kalecki faz referência às expectativas dos agentes. Kalecki (1977 [1943], p.55) afirma que "em um sistema de laissez-faire o nível do emprego depende, em grande parte, do assim chamado estado de confiança” e continua "se esse se deteriora, o investimento privado declina [logo] tudo o que possa abalar o estado de confiança deve ser cuidadosamente evitado, porque causaria uma crise econômica". E, em seguida (1977 [1943], p.59), afirma que políticas de estímulo ao investimento, tal como a redução da taxa de juros, subsídios ou impostos não necessariamente estimulariam o investimento, pois "é incerta a reação dos homens de negócio àquelas medidas".

Apesar de reconhecer a relevância das expectativas, ele não as inclui explicitamente em suas versões mais acabadas dos determinantes das decisões de investir. Contudo, pode-se assumir, conforme sugere Possas (1987, p.125), que o modelo contempla implicitamente expectativas adaptativas; tanto é assim que o próprio Kalecki afirma que "pode-se supor que a taxa de lucros esperada seja função crescente dos lucros correntes 'reais'” (Kalecki, 1977 [1954]). Sua formulação, embora útil para explicar as fases regulares - agentes decidindo sob uma forma específica de convenção -, não é capaz de explicar as alternâncias desprovidas de padrões. As alternâncias presentes no modelo são completamente endógenas e resultam do efeito dual do investimento [este impacta a demanda via multiplicador e, com maior defasagem, a oferta via ampliação da capacidade produtiva]. Para dar conta das flutuações não regulares, o modelo carece da inclusão da confiança nas expectativas formadas adaptativamente, que admitem a projeção do presente para o futuro como possibilidade, não como regra.

Nos capítulos 12 e 22 da T.G. e no artigo cujo objetivo foi cortar as arestas e mal-entendidos da T.G., 'A teoria geral do emprego' (1937), Keynes trouxe aqueles dois conceitos fundamentais para a compreensão tanto das fases cíclicas "bem-comportadas" das economias capitalistas, como de suas quebras: grau de confiança e convenção. Ele afirma que 
Seria insensato, na formação de nossas expectativas, atribuir grande importância a tópicos que para nós são muito incertos. É, portanto, razoável que nos deixemos guiar, em grande parte, pelos fatos que merecem nossa confiança, mesmo se sua relevância for menos decisiva para os resultados esperados do que outros fatos a respeito dos quais o nosso conhecimento é vago e limitado. (T.G., cap. 12, p. 124)

Se, por um lado, as convenções e a confiança associada a elas fazem a economia mudar de posição e até 'desmoronar', ou criam surtos de otimismo, por outro, são elas próprias que criam a estabilidade temporária da economia.

Ao contrário do que temos proposto, Davidson (2003, p.23) escreveu que "Keynes rejeitou a visão de que informações passadas oriundas das especificações de séries temporais forneçam dados confiáveis, úteis, que permitam previsões estocásticas do futuro econômico"; e afirma que "as despesas de investimentos dependem das expectativas exógenas [que seriam as que] Keynes chamou de 'animal spirits'” (Davidson, 1999, p. 53). Para muitos pós-keynesianos, a instabilidade do capitalismo é incontornável e inerente a ele. A irreversibilidade a baixo custo das decisões tomadas e a incerteza levariam a contínuas, bruscas e imprevisíveis revisões nas expectativas, causando a variabilidade ou até a volatilidade da $\mathrm{EMgK}$ e do sistema como um todo. Não é possível, nessa construção, ainda que parcialmente, endogeneizar as expectativas de longo prazo, que seriam fundamentalmente exógenas. Não por acaso, a maioria dos pós-keynesianos rejeita teorizar sobre o longo prazo.

No entanto, Keynes afirmou que, apesar de o passado recente não fornecer dados confiáveis para a tomada de decisões, seria ainda menos razoável dar grande peso àqueles fatores sobre os quais sabemos tão pouco ${ }^{16}$. Logo, o passado recente e o estado atual das coisas são, sim, úteis no esquema proposto por Keynes para a formação de expectativas e para a tomada de decisões, inclusive as de longo prazo; permitindo que possamos fazer predições, até mesmo sobre o longo prazo, em momentos de normalidade ${ }^{17}$.

Em momentos de normalidade, o uso de convenções significa, na tipologia de Keynes, utilizar algum tipo de regra prática - compartilhada entre agentes - para a tomada de decisões sob incerteza, tal como projetar o passado para o futuro com base na opinião média do mercado. Contudo, os agentes atribuem às expectativas assim formuladas um 'grau de confiança' que, de tempos em tempos, pode mudar, e junto com ele, as convenções. Quando diminui a confiança e as convenções se quebram, as flutuações regulares ou semiregulares darão lugar à instabilidade.

\footnotetext{
${ }^{16}$ Keynes, (1982 [1936], p.123).

17 O termo "normalidade" foi utilizado por Keynes nos textos publicados em seus collected writings fazendo referência a períodos em que não se espera mudanças bruscas ou em que a incerteza está dentro de limites aceitáveis. Não é fácil, portanto, definir o que é 'normal'. Em uma definição psicológica, seria a crença na continuidade.
} 
Nesse sentido, Keynes afirma:

Por essa razão, os fatos atuais desempenham um papel que, em certo sentido, podemos julgar desproporcional na formação de nossas expectativas a longo prazo, sendo que o nosso método habitual consiste em considerar a situação atual e depois projetá-la no futuro, modificando-a apenas à medida que tenhamos razões mais ou menos definidas para esperarmos uma mudança (grifos nossos, op. cit., p.124).

Keynes está sendo categórico. Sabemos que existem fatos desconhecidos que afetam o curso dos eventos, mas não temos como dar demasiado peso a estes. Diante de um futuro incerto, aposta-se no prognóstico mais provável para a tomada de decisões; e o mais provável (no sentido de probabilidades subjetivas), exceto quando se têm motivos para crer no contrário, é supor que o estado atual das coisas permanecerá por algum tempo. Esta é a convenção vigente em momentos de normalidade. Esse argumento está explícito na afirmativa de Keynes (op. cit., p. 127): "Esse método convencional de cálculo será compatível com um considerável grau de continuidade e estabilidade em nossos negócios, enquanto pudermos confiar na continuação do raciocínio [itálico no original]".

E o sistema é potencialmente instável porque não depende apenas dos valores esperados das variáveis, mas fundamentalmente da confiança que depositamos neles. Se esperamos que o estado atual das coisas não permanecerá como antes, mas não sabemos como se revelará, o grau de confiança nas previsões anteriores cairá.

Pode-se afirmar, portanto, sem cometer nenhuma distorção da T.G. e sem abandonar conceitos tão caros a ela, como o de incerteza forte e o de instabilidade - muito ao contrário, inteiramente com base nestes -, que as expectativas de longo prazo e o investimento em Keynes tendem a ser, sim, endógenos em momentos de normalidade.

A questão é que as expectativas assim formuladas estão construídas em bases pouco sólidas. Nada garante a realização das mesmas. Nada garante que mudanças bruscas não ocorrerão no curso dos eventos. Por isso, o segundo conceito é fundamental: o grau de confiança, que representa

a maior ou menor convicção nos fundamentos que geraram a previsão, sem ter relação necessária com a probabilidade (subjetiva) associada àquele valor previsto. Dada a (mais ou menos, mas sempre) precária base em que se apoia uma previsão sob incerteza, o grau de confiança se torna sensível à percepção da incerteza, mantendo uma relação inversa a esta: maior incerteza, menor confiança - independentemente de que o valor previsto também seja, ou não, afetado. (Possas, 2015)

O estado de confiança afeta a escala da EMgK ao impactar a confiança na ex- 
pectativa que se formulou sobre o fluxo de rendimentos esperados ${ }^{18}$ e não as próprias expectativas (i.e., seu valor esperado). Ainda que as expectativas sejam mutáveis, não faz sentido pensar que elas sejam extremamente voláteis, pois para isso seria necessário que os fundamentos que as determinam ou seus parâmetros também o fossem. Ainda que passíveis de mudanças, não acreditamos que seus determinantes sofram mudanças bruscas em curtos intervalos de tempo. Por isso, ressaltamos o grau de confiança nas expectativas como o fator mais relevante para explicar as mudanças repentinas no investimento ${ }^{19}$.

Temos, portanto, duas fontes de alterações nas variáveis macroeconômicas. Primeiro, as mudanças endógenas, tal como proposto também no modelo de Kalecki, em que a decepção continuada das expectativas explicará a reversão. E, segundo, as mudanças exógenas, que, mesmo que as expectativas ainda não tenham sido frustradas, poderão ocorrer em virtude de mudanças no grau de confiança, esse sim, exógeno ${ }^{20}$.

Mudanças no grau de confiança, em geral abruptas, dão a tônica dos fatores de instabilidade. Se os agentes têm alta confiança em seus prognósticos, sejam eles otimistas ou pessimistas, estes tendem a se autorrealizar. Se os agentes têm falta de confiança em seu prognóstico, as convenções podem se quebrar. E, quando um sistema de convenções se quebra, surgem as possibilidades de instabilidade, até que outro sistema de convenções seja posto no lugar. Por isso é possível extrair da contribuição de Keynes momentos de estabilidade que são rompidos por outros de instabilidade, que podem se traduzir tanto em crises repentinas como em períodos de expansão.

Economistas críticos do uso da incerteza proposta por Keynes, como Garegnani $(1979$, p. 183), afirmam que "sob incerteza tudo é possível" e argumentam que a ênfase nas expectativas dada por Keynes serve apenas para tornar o sistema indeterminado, juntamente com o investimento. Em suas palavras:

the procedure by which unobservable, 'expected' quantities are used as determinants of the system runs the risk of depriving the theory of any definite results.

\footnotetext{
${ }^{18}$ Uma forma alternativa de pensar o efeito das mudanças no grau de confiança sobre as decisões de investir está presente em Possas (2015). Este autor sustenta que mudanças no grau de confiança não mudam diretamente as expectativas (seus valores esperados), e que seu impacto se dá sobre a taxa de desconto específica do ativo, e não diretamente sobre a EMgK. No entanto, é claro que as decisões de investir no ativo são igualmente afetadas.

${ }^{19} \mathrm{Em}$ termos práticos, a fim de explicar as flutuações não regulares, parece indiferente supor que as expectativas são muito voláteis ou que o grau de confiança o seja. Mudanças em quaisquer das duas grandezas mudaria a EMgK e/ou a taxa de desconto aplicada aos rendimentos esperados, gerando flutuações bruscas. No entanto, na integração proposta, em que as expectativas de longo prazo são endógenas em momentos de normalidade, é possível extrairmos alguma previsibilidade, ficando a indeterminação como um caso importante, mas não geral.

${ }^{20}$ Não é nosso objetivo discutir exaustivamente neste texto as fontes possíveis de mudanças no grau de confiança. Podemos citar como exemplo a piora das condições externas, uma crise na cena política ou mesmo uma situação como aquela prevista por Kalecki eu seu texto "Aspectos políticos do pleno emprego" (1977[1943]).
} 
A inclusão de expectativas, ao invés de uma qualidade, seria um defeito da teoria. Nós argumentamos exatamente o contrário. A ênfase nas expectativas (sob incerteza) e na confiança que se deposita nelas é fundamental num sistema complexo, baseado numa miríade de agentes individuais e permite melhor compreensão da sua dinâmica. Na verdade, sob incerteza os agentes adotam comportamentos defensivos e a convenção se materializa em regularidade do sistema, não em indeterminação.

Além dos períodos de regularidade, as economias capitalistas experimentam com frequência períodos de instabilidade que também precisam ser explicados. No modelo de Keynes, elas são devidas à quebra da confiança depositada em expectativas formadas sob incerteza, dando lugar a flutuações. Logo, ele provê uma teoria na qual a economia capitalista é vista como potencialmente instável, e essa instabilidade potencial está associada essencialmente a mudanças bruscas no grau de confiança. Para que "seja possível restabelecer a recuperação, é necessária a volta da confiança que se afigura tão difícil de controlar numa economia de capitalismo individualista" (Keynes, 1982 [1936], p.144).

Contudo, Keynes não provê um modelo analítico específico para a tomada de decisões de investir, o que é feito por Kalecki; suas contribuições, longe de serem incompatíveis, se complementam. Pode-se considerar que o modelo proposto por Kalecki incorpora uma maneira convencional de formação de expectativas, sem associar a elas um grau de confiança ou supondo (implicitamente) um grau de confiança estável, o que seria compatível com a presença de flutuação cíclica regular e retrataria as fases de 'normalidade' da dinâmica proposta por Keynes.

A convergência da análise do ciclo entre os dois autores, a despeito das diferenças analíticas, é muito evidente. A descrição do ciclo feita por Keynes no capítulo 22 da T.G. não conflita com a explicação das flutuações endógenos presentes no modelo de Kalecki. Isto é, para os dois autores trata-se de uma dinâmica cíclica associada ao efeito dual e defasado do investimento, que é gasto no curto prazo, mas amplia a capacidade decorrido o tempo suficiente, e cedo ou tarde poderá ocorrer uma reversão.

Keynes afirma que tais movimentos cíclicos, "uma vez iniciados não persistem indefinidamente na mesma direção, mas acabam por inverter-se”, e continua: "queremos dizer, também, que existe certo grau reconhecível de regularidade na sequência e duração dos movimentos" (Keynes, 1982 [1936], p.294). Essa leitura das fases cíclicas 'bem-comportadas', e os mecanismos descritos por Keynes para o funcionamento da flutuação cíclica estão em pleno acordo com aquelas descritas por Kalecki.

Keynes (1982 [1936], p.296) afirma:

A explicação do elemento tempo no ciclo econômico, o fato de que em geral tem de decorrer um lapso determinado de tempo antes que se inicie a recuperação, deve ser procurada nas influências que governam a recuperação da EMgK. Há razões dadas, primeiro pela extensão da vida útil dos bens duráveis, em segundo pelas despesas correntes de conservação 
dos estoques excedentes, que explicam por que a duração do movimento descendente deve ter uma magnitude que não é fortuita, que não flutua entre, digamos, um ano agora, e dez anos a próxima vez, mas antes evidencia determinada regularidade.

E prossegue: "enquanto a expansão continua, a maioria dos novos investimentos oferece rendimento corrente que não é insatisfatório” (p.296), ressaltando aí o efeito da variação no nível de atividade sobre o investimento, presente em Kalecki. Reconhecendo também o efeito negativo do aumento do estoque de capital, visto que “(a) desilusão chega porque, de repente, surgem dúvidas quanto à confiança que se pode ter no rendimento esperado, talvez porque o rendimento atual dê sinais de baixa à medida que os estoques de bens duráveis produzidos recentemente aumentam regularmente", explicando a reversão endógena. A depressão continua até que a deterioração e a obsolescência se tornem fortes o bastante para aumentar novamente a eficiência marginal do capital (Keynes, 1982 [1936]). Keynes exalta, como Kalecki, a dinâmica cíclica endógena associada ao investimento ${ }^{21}$, destacando, inclusive, o papel que a depreciação exerce para levar a economia à recuperação.

As passagens acima evidenciam o papel do grau de utilização da capacidade na determinação da dinâmica cíclica associada ao investimento. Porém, Keynes não desenvolveu um modelo analítico, mas apenas descritivo da dinâmica cíclica, abrindo espaço para o uso do modelo mais sistemático que Kalecki construiu a fim de explicar os momentos de normalidade caracterizada pela dinâmica cíclica, cuja regularidade está também presente na T.G. Contudo, não consideramos relevante colocar foco na reversão, porque neste tipo de modelo com estrutura estável é bem conhecido que o sistema econômico reverte necessariamente (apresenta instabilidade dinâmica) e a alternância se verifica.

No entanto, Keynes chama a atenção para a importância de explicar os ciclos em seu conceito mais amplo, para além do ciclo puro, que permita incorporar a instabilidade, caracterizada pela ruptura da estrutura vigente.

As crises ocorrem quando o padrão de alternância é alterado, e isso se verifica quando se quebra o grau de confiança nas expectativas. Ora, temos que lembrar que a incerteza não é eliminada pelas convenções, apenas contornada. "A prática de calma e imobilidade, de certeza e segurança rompe-se de repente. Sem aviso prévio, a conduta humana passa a ser dominada por novos temores e esperanças. As forças do desengano podem repentinamente impor uma nova base convencional de avaliação" (Keynes, 1984 [1937], p.172).

Essa é a questão-chave do nosso argumento. Um modelo fundado no princípio do ajustamento do estoque de capital, sob expectativas adaptativas, é insuficiente para explicar as mudanças mais bruscas no sistema, porém útil para explicar as fases de normalidade, e as contribuições desses autores se complementam.

${ }^{21}$ Diferentemente de Kalecki, Keynes enfatiza também o ciclo de estoques. 


\section{CONCLUSÕES}

$\mathrm{O}$ artigo buscou integrar as visões de Keynes e de Kalecki sobre os determinantes do investimento, a fim de prover melhor compreensão tanto da estabilidade como da instabilidade capitalista, expressos em fases cíclicas com certa regularidade que são eventualmente rompidas.

Nossa proposta envolveu discutir dois pontos centrais: primeiro, que as economias capitalistas tendem a apresentar flutuações regulares - com padrão cíclico aproximadamente identificável - compatível com o chamado comportamento convencional, com reversão endógena, que vigora em momentos de normalidade. O segundo ponto foi mostrar que essa regularidade tende a ser rompida de forma imprevista, dando lugar a flutuações não regulares, explicadas essencialmente pela mudança exógena no grau de confiança nas expectativas de longo prazo e na quebra de convenções. As fases regulares podem ser compreendidas por meio do modelo proposto por Kalecki para explicar as decisões de investir, cuja dinâmica é essencialmente cíclica devido ao efeito dual do investimento. As instabilidades são explicadas por mudanças no grau de confiança nas expectativas assim formadas, que é fortemente impactado por mudanças na percepção da incerteza.

Buscamos justificar que no esquema teórico de Keynes a estabilidade se rompe não porque os agentes revisam suas expectativas repentinamente - até porque os fundamentos econômicos sobre os quais se formam as expectativas não são amplamente mutáveis. Na verdade, é a confiança depositada nas expectativas e sua mudança repentina, decorrente da variação da percepção de incerteza, que fazem a economia flutuar sem padrão regular.

O ponto central de Keynes é mostrar que os agentes formulam suas expectativas sob incerteza, mas agem seguindo algum padrão de normalidade, que caracteriza as convenções. Estas proporcionam em geral maior estabilidade, ancorando a tomada de decisões. Pode-se considerar que o modelo de decisões de investir de Kalecki também tem uma base convencional. Em momentos de normalidade os agentes atuam em acordo com o 'princípio do ajustamento do estoque de capital', levando em conta o grau de utilização e o acesso ao crédito. No modelo de Kalecki, a dinâmica é cíclica - com regularidade em sua 'ciclicidade' -, mas o modelo não é capaz de explicar as flutuações não regulares, uma vez que atribui implicitamente um grau de confiança estável às convenções.

Ao se projetar o passado sobre o futuro, acredita-se mais ou menos que aquelas expectativas assim formuladas se efetivarão. Mas o sistema capitalista experimenta mudanças bruscas não captadas pelo padrão 'regular'. Se muda a confiança que os agentes depositam nesta forma convencional de agir e tomar decisões - o que é capturado pelo modelo de Keynes - a economia flutuará de forma não regular. Assim, os modelos de Kalecki e de Keynes são complementares e a combinação dos dois é útil ao permitir explicar de forma mais completa tais movimentos. 


\section{REFERÊNCIAS BIBLIOGRÁFICAS}

DAVIDSON, P. (1999) "Colocando as evidências em ordem: macroeconomia de Keynes versus velho e novo keynesianismo”. In: LIMA, G. T.; PAULA, L. F. e SICSÚ, J. (Org.). Macroeconomia Moderna. Rio de Janeiro: Campus, 1999. p.35-64.

DAVIDSON, P. (1972) Money and the real word. The MacMillan Press.

DAVIDSON, P. (2003) "Resgatando a revolução Keynesiana”. In: Lima, G. T. \& Sicsu, J. Macroeconomia do emprego e da renda: Keynes e o keynesianismo. Manole, 2003.

GAREGNANI, P. (1979) "Notes on consumption, investment and effective demand: a reply to Joan Robinson". Cambridge Jornal of Economics, 3:2, June.

KALECKI, M. (1977 [1935]) “O mecanismo de recuperação econômica”. In.: MIGLIOLI, J. (org e trad) Crescimento e ciclo das econômicas capitalistas. São Paulo: Hucitec, 1977.

KALECKI, M. (1977 [1943]). “Aspectos políticos do pleno emprego”. In: MIGLIOLI, J. (org). Crescimento e Ciclo das Economias Capitalistas. São Paulo: Hucitec, 1977.

KALECKI, M. (1977 [1954]) Teoria da dinâmica econômica: Ensaio sobre as mudanças cíclicas e a longo prazo da economia capitalista. São Paulo: Nova Cultural, 1977.

KALECKI, M. (1977 [1968]). "Tendência e ciclo econômico". In: MIGLIOLI, J. (org). Crescimento e Ciclo das Economias Capitalistas. São Paulo: Hucitec, 1977.

KEYNES, J. M. (1982 [1936]) A teoria geral do emprego, do juro e da moeda. Tradução de Mário R. da Cruz; revisão técnica de Cláudio R. Contador. São Paulo: Atlas, 1982.

KEYNES, J. M. (1984 [1937]) “A teoria geral do emprego”. In: SZMRECSANYI, T. John Maynard Keynes: economia. São Paulo: Ática, 1984. p.167-179.

LOPEZ, J. \& Mott, T. (1999) “Kalecki versus Keynes on the determinants of investment." Review of Political Economy, vol. 11, n.3 1999.

POSSAS, M. L. (2015) "Uma interpretação de pontos controversos da Teoria Geral de Keynes”. Revista da Associação Keynesiana Brasileira, 2015.

POSSAS, M. \& BALTAR, P. (1983) "O modelo de ciclo econômico de Kalecki". Revista de Econometria.

POSSAS, M. L. (1987) A dinâmica da economia capitalista: uma abordagem teórica. São Paulo: Editora Brasiliense. 